\title{
Productivity issues in the future enterprise - Conclusions and recommendations from the TOPP program
}

\author{
A. Rolstadås \\ Department of Production and Quality Engineering, \\ Norwegian University of Science and Technology \\ N-7034 Trondheim, NORWAY \\ Tel: +47-73593785 Fax: +47-73597117 \\ Arolst@protek.unit.no
}

\begin{abstract}
TOPP is a productivity research programme for the Norwegian manufacturing industry which was completed in 1996 . It studies productivity at two levels: selfaudit and external audit. Both use an enterprise model comprising functions, system variables, cycles, and management philosophies. The external audit in addition uses a model with indicators for economy, external relations, internal relations, and ability to change.

TOPP has recognized the change from a prevailing productivity paradigm based on efficiency in resource consumption to a new performance paradigm putting the customer in focus and taking several other aspects than efficiency into account.

The future enterprises will be characterized by a focus on total quality, globalisation, and a business process-oriented approach. The globalisation will lead to the "virtual enterprise". The virtual enterprise can obtain a competitive position by defining and re-engineering its business processes.

TOPP has made studies in 60 enterprises and has drawn its conclusions from these and given 10 recommendations.
\end{abstract}

\section{Keywords}

Productivity, Modelling, Manufacturing, Information technology, Production management. 


\section{INTRODUCTION}

TOPP is an industrially led researach program directed towards productivity increase in the Norwegain manufacturing industry. It has been sponsored by the Norwegian Resarch Council, and has been executed by the Norwegian University of Science and Technology (NTNU), SINTEF, and the Federation of the Norwegian Engineering Industry (TBL).

TOPP was initiated in 1991 and the program was concluded in March 1996. More than 30 mill. USD has been spent on the progject. About $35 \%$ of this is governmental money.

The TOPP-programme consists of the following subprograms:

- Developing company productivity and competitiveness study

- Implementing industrial improvement actions

- Developing knowledge through research projects

- Long-term competence development

About 60 enterprises has participated in TOPP. 40 of these have done in-depth productivyt studies and are referred to as TOPP enterprises.

TOPP has used the term productivity in a wide sense. Productivity has been defined as "the ability to satisfy the market's need for goods and services with a minimum of total resource consumption". This includes all value adding activities in the enterprise and all factors the enterprise can influence to improve its competitiveness.

The goals of TOPP has been (Andersen, et al., 1996):

- Development and adaption of knowledge about measures aimed at increasing productivity

- $\quad$ Competence development in the TOPP enterprises

- Competence development at NTNU/SINTEF

- Motivation and information about activities aimed at increasing productivity

- Implementation of measures aimed at increasing productivity in Norwegian companies

- At least 5 companies shall obtain results that set outstanding examples for others.

- At least half of the companies shall obtain specific results within time and quality such that others can benefit from the experience.

- Contribute to the implementation of education and continued education programmes within productivity

- Educate 10 Dr.ing. (Ph.D.)

- Establish a masters degree in technology management

- Establish a continued education course on productivity

TOPP has put main focus on time and quality as competitive factors.

The significance of the TOPP results compared to previous work can be summarized in the following key items: 
- A new enterprise model has been developed which is better suited for performance measures than previous models.

- A set of indicators has been derived based on both qualitative and quantitative information.

- A self assessment tool based on business processes has been developed and supplied to industry.

- Industrial awareness has been developed and general guidelines have been supplied for improved industrial performance.

\section{THE FUTURE PRODUCTIVITY PARADIGM}

Productivity is a term usually associated with efficient resource utilisation, and many still today measure productivity as the a ratio between output and resources consumed. Typical members are output per employee or capital and number of production hours per machine, etc. This type of thinking has led to suboptimization and has failed to direct the management focus to the most productivity influencing factors. This type of thinking can never satisfy the intentions laid down in the wide definition of productivity given in the previous chapter.

Productivity in the classical sense is by no means a new issue. It is sufficient to refer to early methods such as (Rolstadås, 1995):

- Taylor's Scientific Management

- Frank and Lillian Gilbreth's time and motion studies

- The Henry Ford assembly line

- The learning curve

- The Hawtorne studies

In the future enterprise process thinking is dominating and benchmarking is frequently used to improve productivity (Andersen and Peterson, 1994).

The future enterprise is "lean" or "agile". The customer is in focus. All activities in the company must add value for the customer. Otherwise they represent a waste of resources. The customer worries about price, quality, service, and delivery. Total quality management has become a new topic addressing all these problems. Actually, it goes far beyond product quality. It looks at quality in every link and every activity. The customer's expectations must be exceeded.

The future enterprise will compete in a changed market characterised by (Rolstadås, 1995):

- Declining demand

- Global competition

- Customer in focus

- Life cycle requirements

- Environment protection restrictions

This market is international. Each business process in the company must be benchmarked against the very best world-wide (Rolstadås, 1993). But only the market is international. The same is true for the company. A successful 
competitive company may place its development activities in region $\mathrm{A}$ and its manufacturing in regions $B$ and $C$. These activities may be moved at any time to the region offering the most favourable conditions. The company will focus on its core business processes and may outsource the rest to more-competitive suppliers.

These suppliers may have long-term contracts including technological development. The company will establish a strategic alliance with its suppliers. This may even extend to the customers or vendors. This is what is meant by the virtual company (Kimura, 1993; Rolstadås, 1994). The virtual company consists of a number of units geographically dispersed but managed as one total unit, although the subunits may be under separate management.

Globalisation is a very important development trend in industry. Another important aspect in industrial development in process oriented thinking (Harrington, 1991). As competition becomes global, it also becomes more fierce. To stay competitive is a continuous race. Industry must continuously improve itself. There is not time to "lean back and take a break".

In the future enterprise the classical way of measuring productivity must be released by a new and more holistic approach. The prevailing productivity paradigm focusing on efficiency in the use of resources, must be replaced by a new productivity paradigm focusing on performance. Performance regards efficiency as one out of several factors that determine productivity (Rolstadås, 1995). One of the first to define measures for performance were Sink and Tuttle (Sink, 1985; Tuttle, 1989). They regarded effectiveness, efficiency, quality, productivity, quality of work life, innovation and profitability/budgetability.

\section{THE TOPP MODEL}

TOPP has developed two sets of methodologies for measuring productivity in a company (Moseng and Bredrup, 1993):

a. Self-audit based on a questionnaire answered by the companies.

b. External audit performed by experts analysing the companies.

There are some similarities between TOPP and the methodolgy used for awards like Malcom Baldrige, Deming, and the European Quality Award. However, TOPP focuses on more aspects concerning the competitiveness of the whole company, while the awards mentioned have their main focus on quality.

Both methodologies require an enterprise model suitable for understanding and measuring differences in performance between companies.

The TOPP model is based on a three-dimensional performance model as shown in figure 1. Effectiveness indicates to which extent customer needs are satisfied, efficiency indicates to which extent the total resources of the company are efficiently utilized, and ability to change indicates to which extent the company is prepared to adapt to a changed market. 


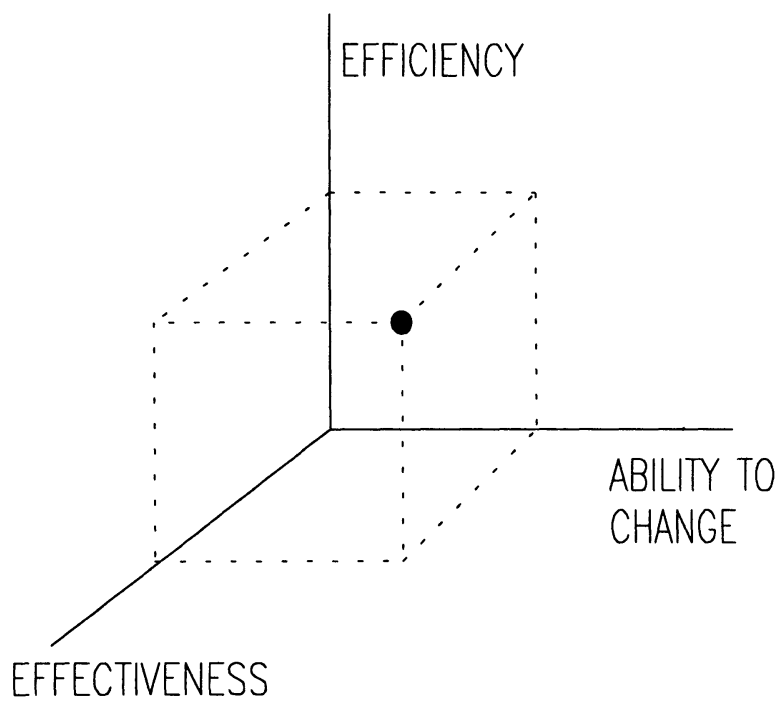

Figure 1 Performance measurement.

The self audit is performed by using a questionnaire which is answered by each company. The questionnaire contains three parts (Rolstadås, 1995):

- Part 1 - Facts about the company, products, cost, finance, manpower, capacities, production, etc.

- Part 2 - Overall evaluation of different functions and system variables. This part is answered confidentially by 20 individuals in the company.

- Part 3 - Detailed evaluation of primary and support functions and system variables (products, facilities, personnel, etc.). This part is answered by specialist groups in the company. Management is represented in all groups.

The self audit is based on a model break down of the enterprise in four different ways (Rolstadås, 1995):

- Primary and support functions

- System variable

- Cycles

- Management philosophies

The external audit uses external experts. The company is analysed in two different ways (Rolstadås, 1995):

- Company "split-up" using the same breakdown as for the self audit.

- Company as a whole using indicators focusing on the overall performance of the whole enterprise (see figure 2). 

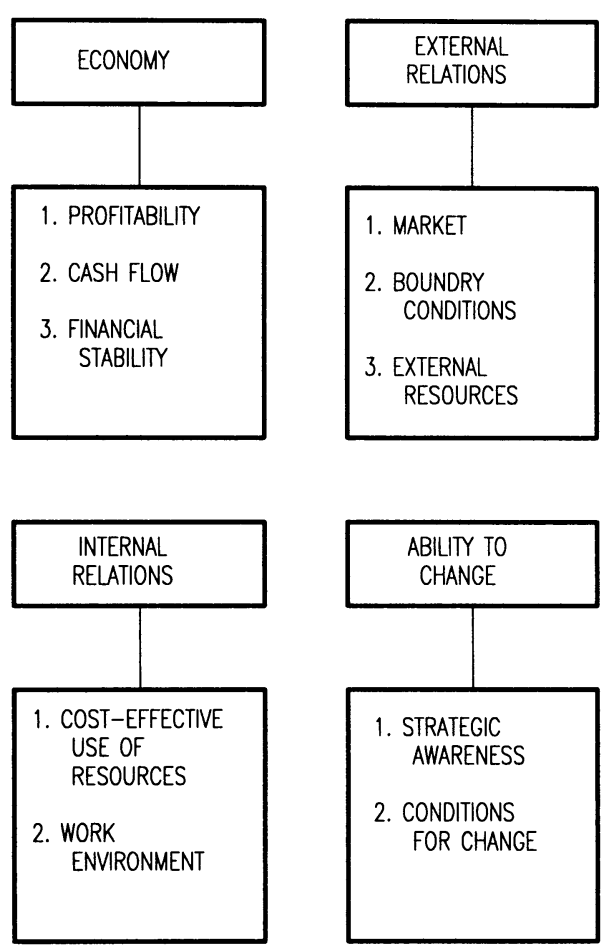

Figure 2 Company level-analysis areas.

The results of the external audit are presented in a profile chart for enterprise. Figure 3 shows an example.

The TOPP methodology has been refined to provide a tool of enterprises to assess their productivity development independent of any external help. The method is called self assessment and includes six steps:

1. Identification of critical and important business processes in the company.

2. Selection of areas to be analysed and appropriate indicators of performance measure.

3. How to organise self assessment.

4. Data collection

5. Presentation of results

6. Actions based on evaluation of results 
$\begin{array}{lllllll}1 & 2 & 3 & 4 & 5 & 6 & 7\end{array}$

\begin{tabular}{|l|l|}
\hline System & 1. Products \\
variables & 2. Faciclities \\
3. Equipment \\
4. Personnel \\
5. Org./mgt. systems
\end{tabular}

Figure 3 Example of profile chart from TOPP external audit.

\section{TOPP CONCLUSION AND RECOMMENDATIONS}

Based on the findings from TOPP productivity studies and associated research project, a total of 13 conclusions have been drawn concerning external conditions, internal conditions and internal processes.

These conclusions are (Andersen, et al., 1886):

\section{External conditions}

1. Stable and well developed business relations to other participants in the production chain is a vital condition for effective value adding.

2. The best companies have developed a customer focus throughout the entire organisation.

3. Most companies are insufficiently prepared for the challenge the development towards virtual enterprise represents.

\section{Internal conditions}

4. The best companies have internationally competitive products.

5. The best companies apply considerable resources on continuous technology development.

6. The best companies have develped simple and decentralised organisational and decision-making structures and focus on business processes. 
7. The majority of the companies base strategic as well as operational management on incomplete or inaccurate measurement systems.

8. The majority of the companies need better concepts for production management.

\section{Internal processes}

9. Many companies which have invested in modern production equipment are unable to fully exploit the potential this represents.

10. Most companies give procurement low priority and have not taken sufficiently advantage of the possibilities new types of supplier partnership represent.

11. The best companies emphasise overall co-ordination and integration of the product development process and work closely with potential customers.

12. Only a few companies have organised improvement processes which systematically comprise all the company's activities.

13. The best companies focus on time and quality as competitive parameters.

In addition to these conclusions, 10 recommendations have been made for industry, government, and universities. These are (Andersen, et al., 1996):

\section{Recommendations for industry}

1. Carry out systematic productivity measurement based on the organisational structure and company culture.

2. Develop the virtual enterprise and rationalise the logistics chain.

3. Develop a customer focused organisation.

4. Implement new organisational structures based on employee participation.

5. Goal oriented competence development to support and further develop the company's core competence.

$\underline{\text { Recommendations for government agencies and institutions }}$

6. Prepare for development of industrial competitiveness.

7. Continuous focus on productivity and competitiveness.

8. Focus on productivity development in small and medium companies through transfer of research results within productivity.

\section{Recommendations for universities and research institutions}

9. Establish a productivity centre in a network.

10. Develop an improved education and continuous education programme within productivity related subjects.

TOPP has been a successful program and has achieved all its major goals. The TOPP method has been applied in other international projects. In addition a similar program is set up within the European Union. The program is called ENAPS - The European Network for Advanced Productivity Studies (Rolstadås and Strandhagen, 1995). 


\section{REFERENCES}

Andersen, B. \& P.G. Pettersen (1994), The Basis of Benchmarking: What, how, when, and why, in 'Proceedings for 1994 Pacific Conference on Manufacturing', Djakarta, Indonesia.

Andersen, B., E. Printz Moe, B. Moseng \& A. Rolstadås (1996), Produktivitet og konkurranseevne i norske bedrifter, ad Notam, Oslo (in Norwegian).

Harrington, J.J. (1991), Business Process Improvement: The Breakthrough Strategy for Total Quality, Productivity, and Competitiveness, McGraw-Hill, New York, N.J.

Kimura, F. (1993), Virtual Manufacturing Environment, 'IMS Globemann 21 Meeting', Kyoto.

Moseng, B. \& H. Bredrup (1993), 'A Methodology for industrial Studies of Productivity Performance: Production Planning \& Control', 4 (3).

Rolstadås, A. (1993), Manufacturing Industry Benchmarking, in 'Proceedings for APMS'93', Elsevier Science Publishers.

Rolstadås, A. (1994), Beyond Year 2000 - Production Management in the virtual Company in 'Proceedings for IFIP WG5.7 Conference on Evaluation of Production Management Methods, Gramudo, Brazil, March', Elsevier Science Publishers.

Rolstadås, A. (ed.) (1995), Performance Management - A Business Process Benchmarking Approach, Chapman \& Hall.

Rolstadås, A. (1995), TOPP - A Productivity Improvement Programme for Norwegian Industry, Norwegian Institute of Technology.

Sink, D. Scott (1985), Productivity Management: Planning, Measurement, and Evaluation, Control, and Improvement, John Wiley \& Sons, New York.

Sink, D. Scott \& T.C. Tuttle (1989), Planning and Measurement in your Organization of the Future, Industrial Engineering and Management Press, Norcross.

Strandhagen, J.O.\& A. Rolstadås (1995), ENAPS - A European Network for Andvanced Productivity Studies, SINTEF, Trondheim.

\section{BIOGRAPHY}

Asbjørn Rolstadås is professor of production and quality engineering at the Faculty of Mechanical Engineering of The Norwegian University of Science and Technology. His research covers topics like numerical control of machine tools, computeraided manufacturing systems, productivity measurement and develoment, computeraided production planning and control systems and project management methods and systems. He is a member of The Royal Norwegian Society of Sciences, the Norwegian Academy of Technical Sciences, the Royal Swedish Academy of Engineering Sciences and APICS. He serves on the editorial board of the journal Computers in Industry, and is the editor of the International Journal of Production 
Planning and Control. He is past president of IFIP and past chairmen of IFIP TC5 and WG5.7. He is also past president of the Norwegian Computer Society and the Nordic Data Processing Union. 